\title{
EXPERIÊNCIAS DE VIOLÊNCIA INTRAFAMILIAR ENTRE ADOLESCENTES EM CONFLITO COM A LEI
}

\section{EXPERIENCES OF INTRAFAMILIAR VIOLENCE BETWEEN ADOLESCENTS IN CONFLICT WITH THE LAW}

Isabel Maria Sampaio Oliveira Lima* Miriã Alves Ramos de Alcântara**

Kátia Virgínia Dórea Almeid ${ }^{* * *}$

Vânia Sampaio Alves ${ }^{* * * *}$

\begin{abstract}
Lima IMSO, Alcântara MARd, Almeida KVD, Alves VS. Experiências de violência intrafamiliar entre adolescentes em conflito com a lei. Rev Bras Crescimento Desenvolv Hum. 2006;16(2):16-24.
\end{abstract}

\begin{abstract}
Resumo: O presente estudo tem como objeto discutir experiências de violência intrafamiliar relatadas por adolescentes autores de ato infracional no Estado da Bahia em cumprimento de medida socioeducativa de internação. Revisa aspectos normativos relacionados com o grupo infanto-juvenil e apresenta os resultados de uma investigação realizada em convênio com a Vara da Infância e da Juventude da cidade do Salvador. Considera-se a importância de políticas públicas de apoio à família na perspectiva dos direitos humanos, com foco no crescimento e desenvolvimento do grupo infanto-juvenil. A condição de vulnerabilidade enfrentada pelos adolescentes é relacionada ao necessário esforço que deve ser empreendido conjuntamente pela família, pela comunidade e pelo Estado para respeitar sua dignidade como pessoa humana.
\end{abstract}

Palavras-chave: Violência intrafamiliar. Direito da criança e do adolescente. Adolescente em conflito com a lei. Família.

\section{INTRODUÇÃO}

Há muitos anos a violência contra o grupo infanto-juvenil emerge como objeto de estudo a partir de diferentes perspectivas. Uma vertente tem discutido o impacto dos meios de comunicação no comportamento agressivo de crianças e jovens ${ }^{1,2}$. Os estudos de Sanchez e Minayo ${ }^{3}$ e de Roure ${ }^{4}$ analisam indicadores epidemiológicos, suas determinações históricas e as narrativas sobre o exercício da violência contra crianças e adolescentes. Em relação à violência praticada pelos mais próximos ao convívio infanto-juvenil, autores como Rosa ${ }^{5}$ e Finkelhor e Williams ${ }^{6}$, evidenciam, dentre outros aspectos, a complexidade dos laços de afeto e de respeito dentro da família. A pesquisa de Fontes ${ }^{7}$, com nove famílias de diferentes nacionalidades residentes nos Estados Unidos, contribui para a compreen-

Juíza de Direito,Doutora em Saúde Pública pelo Inst. de Saúde Coletiva, Universidade Federal da Bahia (ISC-UFBA). Docente da Universidade Católica do Salvador (UCSAL). End. para correspondência: Rua Carmem Miranda 326 Ap 902 Pituba CEP 41.820-230 Salvador- Bahia. E-mail: isabelmsol@compos.com.br

** Psicóloga, Doutoranda em Saúde Pública, Instituto de Saúde Coletiva, Universidade Federal da Bahia (ISCFBA).E-mail: alcantaramiriam@hotmail.com

*** Assistente Social, Especialista em Terapia de Família. Email: katiadorea@ig.com.br

***** Psicóloga, Doutoranda em Saúde Pública. Instituto de Saúde Coletiva, Universidade Federal da Bahia (ISCUFBA).E-mail: vaniasampa@yahoo.com.br 
são dos aspectos culturais implicados no abuso sexual contra seus filhos.

Nestas perspectivas convergem campos disciplinares visando compreender estilos de vida, concepções parentais de criação e práticas baseadas em formas diversas de violência em suas repercussões para o comportamento das crianças enquanto vítimas. Estudos relevantes aliam abordagens sociológicas à perspectiva psicológica, econômica e jurídica ${ }^{8}$, evidenciando a importância da implantação de medidas preventivas de amplo espectro junto às famílias. Entretanto, e apesar do fenômeno da violência familiar estar sendo analisado de forma ampla na literatura científica, a relação entre este tipo de violência e a condição do adolescente em conflito com a lei, destaca a atualidade de investigação nesta área ${ }^{9-12}$.

Diferentes aspectos convergem na abordagem deste objeto de investigação: saúde, crescimento e desenvolvimento de crianças e adolescentes, limites e possibilidades culturalmente organizados para a formação da personalidade ou self. Esta vertente de análise sobre a experiência de violência intrafamiliar entre os adolescentes autores de ato infracional implica em apreender concepções relativas ao significado da infância e da adolescência, em muitos aspectos conflitantes, presentes na organização das práticas de atenção à criança e ao adolescente no Brasil.

A investigação da realidade do adolescente em conflito com a lei plasma, por si só, vários níveis de complexidade de análise. Em referência ao nível humano, existe um compromisso ético em relação à dignidade da pessoa, ao seu respeito e à preservação ontogenética. No que tange aos marcos legais, destaca-se a conquista da civilização, a partir de novembro de 1989 - a Convenção das Nações Unidas sobre os Direitos da Criança (CDC) - para garantir à população infanto-juvenil o reconhecimento de seu status diferenciado de sujeito de direito e de pessoa em fase peculiar de crescimento e desenvolvimento ${ }^{13}$.

O Brasil assimilou os princípios da teoria jurídica da proteção integral à criança e ao adolescente, consubstanciado na CDC de 1989. O avanço normativo nacional está expresso na Constituição Federal e na Lei nº 8.069 de 1990, Estatuto da Criança e do Adolescente (ECA $)^{14}$. Apesar de existir uma mobilização de vários setores em torno da superação da prática da violência familiar, seguida de uma divulgação sobre a importância de considerar como intoleráveis os castigos físicos e a violência, pretensamente correcionais, as diversas formas de reprimir crianças e adolescentes diante de seus comportamentos considerados por seus pais ou familiares como inadequados ou impróprios, são práticas que ainda persistem. A recorrência de atos de violência contra a criança afeta, além da sua integridade física e psicológica, os princípios estruturadores da CDC. Ademais, compromete algo de valor intangível, isto é, a auto-estima do adolescente, sua confiança nas relações com os adultos e na relação futura com seus próprios filhos ${ }^{15}$.

O presente estudo analisa, em um grupo de adolescentes em cumprimento de medida socioeducativa de internação nos termos do artigo 112, inc. VI da Lei ${ }^{0} .8 .069$ de $1990^{+}$, relatos da experiência de violência na família.

\section{A criança e a violência no contexto familiar}

A aprendizagem do comportamento violento foi analisada por diversas correntes de investigação, sendo uma das mais profícuas a desenvolvida por Albert Bandura e colaboradores ${ }^{16}$. Em suas observações do ambiente fa-

Nos termos da Lei no 8069/90: art.112. Verificada a prática de ato infracional, a autoridade competente poderá aplicar ao adolescente as seguintes medidas: VI - internação em estabelecimento educacional. 
miliar de adolescentes que praticavam infrações, os autores puderam identificar nos padrões de discursos parentais a principal fonte de modelos para a expressão de agressividade por parte dos jovens. Em estudos subseqüentes, demonstrou-se que a aprendizagem do comportamento é mais eficaz quando a pessoa segue o modelo em uma observação vicária, o que evidencia o poder da experiência para a atuação futura ${ }^{17}$.

A aprendizagem de comportamentos violentos depende da vivência de violência na vida real e de alguns aspectos individuais do expectador de acordo com a teoria dos efeitos preparatórios de Berkowitz ${ }^{18}$. A teoria desenvolvida por Huesmann ${ }^{19}$ analisa os roteiros adquiridos durante a infância e como os mesmos são utilizados como guias para o comportamento social e resolução de problemas no futuro ${ }^{1}$.

O campo de investigação que relaciona dimensões da vida da família e a prática de infrações de seus membros adolescentes tem desenvolvimento recente com os primeiros estudos relevantes para compreensão de fatores de risco e proteção na família datando da década de 1950 20. Esses estudos já assinalavam a influência da relação do adolescente com as figuras parentais. Analisando grupos de caso-controle compostos por jovens do sexo masculino, verificou-se que $90 \%$ dos adolescentes autores de ato infracional viviam em famílias cujos membros consumiam álcool, apresentavam histórico de envolvimento com a criminalidade e possuíam valores mutáveis. Os marcadores para predisposição de filhos à prática de atos infracionais combinam, em uma seqüência hierárquica quanto ao seu impacto: estilo disciplinar imposto ao adolescente pelo pai; supervisão do adolescente pela mãe; manifestação de afeto do pai em relação ao filho; expressão afetiva da mãe e coesão familiar. Tais características foram analisadas em famílias de adolescentes vizinhos dos sujeitos do estudo, mas que não praticaram infrações, sendo en- contradas distinções positivas quando à coesão familiar e à supervisão materna mostrando-se os adolescentes menos propensos a tais práticas $^{20,21}$.

O envolvimento em práticas análogas ao crime na adolescência e a sua continuidade na vida adulta são influenciados por acontecimentos da infância em reação aos quais se iniciam atitudes anti-sociais que tendem a encadear-se a relações genitores-filho baseadas em maustratos e punição ${ }^{20}$.

Estudos com resultados convergentes aprofundaram o interesse na investigação de trajetórias de desenvolvimento e na identificação dos eventos que influenciam na continuidade da prática de infração durante a vida adulta $^{22,23}$. As práticas parentais percebidas pelo adolescente como severas, inconsistentes quanto à monitoração e conflituosas na infância encontraram significância nos eventos de trajetórias de adolescentes autores de atos infracionais ${ }^{24}$.

De acordo com estudos realizados por Dias $^{25}$, a interação com a família constitui um dos fatores que, juntamente com a escolaridade, mais contribui para o comportamento dos adolescentes em conflito com a lei. A autora, tendo realizado sua investigação com 4.245 jovens autores de atos infracionais, identificou que $35 \%$ deles vivenciaram algum problema intrafamiliar. O estudo evidenciou igualmente que a maioria das famílias dos jovens que praticaram alguma infração era formada apenas por um dos pais, a chamada família monoparental.

Estudos desta natureza se justificam por vários motivos: pela singularidade desta fase do desenvolvimento humano; pela importância da família e da natureza dos vínculos, já que é através desta que se constroem para si e para o mundo; pela definição dos marcos legais e pelo desafio consubstanciado na necessária formulação de políticas públicas para enfrentar a violência contra o segmento infanto-juvenil. 


\section{MÉTODO}

O presente estudo foi realizado em convênio com a Vara da Infância e da Juventude especializada em adolescentes autores de atos infracionais na cidade de Salvador e na Execução das Medidas Socioeducativas do Estado da Bahia, Brasil.

A coleta de dados ocorreu no período 2001-2002. Neste período, encontrava-se em cumprimento da medida socioeducativa de internação o total de 298 educandos, sendo 186 com residência no interior do Estado e 112 na capital. Participaram da pesquisa 120 adolescentes, perfazendo $40,3 \%$ dos educandos. Os sujeitos foram selecionados entre o total de educandos em cumprimento de internação decretada em Ação Socioeducativa Pública nos termos do artigo 112, inciso VI da Lei no 8.069 de 1990. Deste conjunto apenas 12 eram do sexo feminino.

As entrevistas foram realizadas por profissionais do Serviço Social, de Direito e de Psicologia. Os adolescentes foram entrevistados individualmente, a partir de um roteiro semiestruturado, com questões relativas às suas experiências pessoais de violência intrafamiliar em suas trajetórias de vida e anteriores à prática do ato infracional que ensejou a aplicação da medida socioeducativa então em curso.

As entrevistas foram gravadas em fitas de áudio com o consentimento informado dos adolescentes e a autorização do juiz competente. Após a transcrição literal do conteúdo das entrevistas os dados foram organizados e analisados de acordo com a identificação de núcleos temáticos marcados de acordo com a técnica de análise discursiva de Bardin ${ }^{26}$. O desenho metodológico adotado nesta pesquisa é de natureza qualitativa. A opção por essa abordagem baseia-se no interesse em compreender a complexidade de um fenômeno que decididamente não se limita a dados estatísticos.

\section{RESULTADOS E DISCUSSÃO}

As muitas formas de violência no ambiente familiar constituem mecanismos perversos de aprendizagem da violência entre crianças e adolescentes de todas as classes sociais. Os golpes, os tapas, os pontas-pé, o uso de cinturões, as cordas, as palmatórias, além dos beliscões e dos golpes na cabeça, são agressões mecânicas comuns no ambiente familiar dos adolescentes entrevistados, empregados com o propósito de corrigir o comportamento dos filhos. As agressões térmicas, ainda que mais esporádicas, também se manifestam, envolvendo o emprego de água quente ou cigarros contra crianças como forma de castigos corporais. As agressões sexuais representam, por sua vez, o aviltamento do corpo e da intimidade da criança e do adolescente, humilhando a vitima e, por vezes, culpabilizando-a e gerando sofrimento psíquico. As agressões emocionais se constituem em formas reiteradas de humilhação, mediante emprego de nomes degradantes, gestos, depreciações, palavras torpes proferidas contra as crianças e os adolescentes, ora comparando-os às figuras ou imagens que representam objeto de escárnio ou discriminação nos meios de comunicação de massa, ora comparando-os a determinados animais. Muitas vezes o comportamento violento dos pais e familiares é banalizado ou considerado justificadamente necessário, conforme os valores de cada família e comunidade, podendo ocorrer em todas as classes sociais e adquirir, às vezes, formas cruéis. Ainda que o fenômeno da violência intrafamiliar apresente variação espaço-temporal e conteúdos culturais diversos ${ }^{7}$, a forma como afeta crianças e jovens sempre guarda o mesmo gosto amargo. A adolescência pode ser vivenciada como um processo no qual ocorrem alterações de caráter biológico, gerando, entre outras transformações, mudanças físicas e psicológicas que podem ser seguidas por experiências de perplexidade, estranhamento, angús- 
tia e dúvida. Este movimento deve ser acompanhado pela família, mas quando a própria família mantém um padrão violento evidenciando, muitas vezes, níveis diversos de sua própria desestruturação, os filhos trazem impressas estas molduras de desafios em suas trajetórias de vida e nas suas relações sociais.

A análise das entrevistas revela que $92 \%$ dos adolescentes já haviam experimentado, pelo menos uma vez, algum tipo de violência no ambiente familiar, sendo a mais comum a classificada na forma mecânica. Do total dos adolescentes, 89,6\% revelaram que as agressões mecânicas ocorreram mediante aplicação de distintos meios: surras, golpes na cabeça, emprego de palmatórias, beliscões e pontas-pé, além de mordidas ou ataques provocados por cães. Com respeito às surras, foram referidos os seguintes objetos utilizados tanto pelos pais, padrastro, madrastra, tio, tia, irmão, cunhado ou pelo avô/avó: cabo elétrico dobrado, pedaço de madeira, sandália, cinturão, correia, cabo de machado, corrente, mangueira e garrafa. Com respeito às agressões térmicas, que abarcam $6,1 \%$ das referidas, se encontram as queimaduras provocadas pelo lançamento de água quente, de óleo de cozinha quente e de azeite de dendê fervendo. Com respeito às agressões sexuais, mencionadas por $4,3 \%$ dos educandos, foram identificadas situações de manipulação de órgãos genitais, relação íntima do padrastro ou tio com rapazes e um estupro.

Do total dos adolescentes entrevistados, apenas 5,0\% não especificaram a modalidade das agressões e não informaram sobre o agressor familiar: preferiram o silêncio que foi rompido pelo pranto de alguns durante a entrevista. Apenas 3,0\% dos adolescentes entrevistados não fizeram qualquer menção às violências e afirmaram não recordar de agressões sofridas por eles no ambiente intrafamiliar. Conforme dados apresentados na Tabela 1, o pai foi apontado como o principal agressor pelos adolescentes entrevistados.
Tabela 1 - Caracterização das modalidades das agressões e dos agressores no ambiente familiar conforme os adolescentes em conflito com a lei na cidade de Salvador, 2001 a 2002.

\begin{tabular}{lcc}
\hline VARIAVEIS & $\mathbf{N}$ & $\mathbf{\%}$ \\
\hline Modalidade das agressões & & \\
Mecânicas & 108 & 89,6 \\
Agressões térmicas & 7 & 6,1 \\
Agressões sexuais & 5 & 4,3 \\
& & \\
Agressores & & \\
Pai & 38 & 32,1 \\
Mãe & 22 & 18,4 \\
Padrasto & 15 & 12,8 \\
Avô/Avó & 20 & 16,9 \\
Madrasta & 7 & 5,7 \\
Tio & 6 & 4,6 \\
Irmão & 6 & 4,6 \\
Cunhado & 6 & 4,6 \\
\hline
\end{tabular}

Autores como Costa e Lima ${ }^{27}$ ressaltam a importância de não negligenciar o significado da presença familiar junto aos adolescentes. Esta presença deverá estar baseada na sensibilidade humana “porque é a partir dela que podemos dar nossa contribuição para que o adolescente venha a viabilizar-se como pessoa, cidadão e futuro trabalhador, trilhando o caminho do desenvolvimento pessoal e social” (p.46). Aspectos relativos à própria identidade, auto-estima e à autoconfiança do adolescente não podem ser subestimados por suas respectivas famílias, cujo papel, juntamente com o dos professores, é o de proporcionar condições que gerem aquisições para o desenvolvimento. Quando o jovem pratica um ato de infração está revelando sua fragilidade. A este respeito, Lima e Alves ${ }^{28}$ assinalam que: no momento da dificuldade do adolescente em conflito com a lei, surpreendido em sua crise juvenil, ponderando sobre seu acervo de recursos de resiliência, a família do adolescente é convidada a pensar sobre sua responsabilidade, sobre sua atitude educativa e sobre sua própria vocação de humanidade. (p.246)

É relevante a distinção feita por Dor 29 quando, ao tratar do papel da família com rela- 
ção aos seus membros, expressa que há famílias capazes de impulsionar, enquanto outras promovem uma ação inversa, a de expulsar. A primeira ação não implica na perda do enraizamento familiar, já a segunda, promove a separação. Tratando-se de violência familiar, independentemente das modalidades das agressões sofridas - seja mecânica, térmica ou sexual - se apresenta com a configuração de uma dor. Esta dor, mesmo quando não expressa em palavras, vai tomando formas às vezes sutis, às vezes mais evidentes, que se projetam nas relações sociais dos adolescentes. A violência familiar, comumente denominada de "maus-tratos” tem sido racionalizada, através dos tempos, pelas mais variadas e conhecidas justificativas: desde práticas e crenças religiosas até por motivos disciplinares e educacionais ${ }^{5}$.

Estes dados evidenciam que, a promoção do direito infanto-juvenil implica na implantação de políticas públicas específicas e de medidas de proteção previstas na Convenção das Nações Unidas sobre Direitos da Criança, na Constituição Brasileira e no Estatuto da Criança e do Adolescente. As ações promocionais podem ser traduzidas na adoção de políticas de proteção às famílias, garantia de acesso à educação e aos serviços de saúde, com assistência contínua da psicologia e do serviço social, da advocacy e com a perspectiva de inserção das famílias em programas de prevenção contra a violência, programas de integração familiar ou de acompanhamento terapêutico para algum membro específico.

\section{CONSIDERAÇÕES FINAIS}

Discursos e imagens veiculadas sobre infância e adolescência no Brasil são marcados pela plurivocalidade em uma multiplicidade de significações. Um dos coros corresponde às vozes progressistas que assimilam e defendem o paradigma da proteção integral do segmento infanto-juvenil. Esta vertente integra setores da sociedade organizada que evocam os princípios do Estatuto da Criança e do Adolescente, fundados no exercício da cidadania em contexto democrático. Em um tom diverso, ecoa o discurso retrógrado que tende a ressaltar o caráter transitório da infância e da adolescência, pugnando pelas práticas estritamente assistencialistas e repressoras ${ }^{13,30}$.

Os traços essenciais dessas matrizes de significações vêm organizando a história da atenção à criança e ao adolescente, em muitos aspectos regidos por decisões políticas com base em interesses econômicos, que não privilegiam as demandas dessa faixa da população ${ }^{30}$.

Entretanto, a concepção que tende ao paradigma da situação irregular da infância e da adolescência ${ }^{13}$ pode ser encontrada ainda entre os agentes das práticas de cuidado. Do ponto de vista das crianças e adolescentes, o sofrimento experimentado pelas agressões no contexto familiar tem um impacto diferenciado: advém dos próprios familiares, pais e pessoas do seu convívio mais próximo. Quando vítimas de violência intrafamiliar, a criança e o adolescente se encontram em uma situação de dupla vulnerabilidade. A primeira, relativa à própria agressão e ao sofrimento que, de per si, já representam para a vítima, do ponto de vista físico e psicológico. A segunda, relativa à identidade do agressor, pois, a família é compreendida como círculo de acolhimento e de cuidado. Deste modo, aqueles que deveriam ser os responsáveis pelo cuidado, pela atenção, pelo suporte, tanto pelos vínculos biológicos parentais quanto pela relação afetiva, assumem o papel de agressores, rompendo ou fragilizando ainda mais a relação de confiança da criança e do adolescente.

A relação familiar marcada pelo açoite da correia, pelo cinturão de couro, pela vara que fere as costas, pelas palmadas ou golpes diretos, pelas queimaduras, deixam a relação da criança ou do adolescente com o mundo externo ainda mais vulnerável. As reações infanto- 
juvenis diante de situações de sofrimento intrafamiliar são diversas. No estudo feito com vítimas da violência, Mournier e Andujo ${ }^{31}$ identificaram vulnerabilidade no enfrentamento de situações traumáticas. Esta vulnerabilidade foi percebida pelas autoras como potencial alienação e negação destas experiências, seguidas, por determinadas reações comportamentais que necessitam ser analisadas dentro do contexto de vida. O estudo demonstrou, além disso, que estes jovens reagiram com o comprometimento emocional em suas relações sociais.

Quanto à relação entre violência doméstica e ocorrência de bulling na escola, foi constatada uma correspondência positiva evidenciando, no entanto, que a condição de vulnerabilidade da criança e do adolescente, limita sua capacidade de reagir diante de ofensas, chacotas, críticas agressivas, ameaças, exposição às críticas e às humilhações, mesmo que elas venham de pessoas de sua mesma idade e ambiente ${ }^{15,32}$.

Em contrapartida, estudos revelam que as famílias incluídas em programas de assistência, ainda que sejam políticas públicas de caráter compensatório, tem maiores chances de demandar ajuda à equipe do serviço social ou à equipe interdisciplinar para seus filhos ${ }^{33,34}$.

Em um estudo com 2.760 famílias, Berger ${ }^{35}$ identificou que as características demográficas, a depressão materna, o abuso de álcool pela mãe e os padrões de violência intrafamiliar, podem contribuir de forma significativa para as agressões contra a criança. A baixa renda na família monoparental também foi identificada como um fator relacionado à violência intrafamiliar, em maior proporção de que em famílias biparentais com o mesmo nível socioeconômico.

Conceitos como violência, maus-tratos, abuso e exploração sexual são importantes, mas devem ser tomados como peças acessórias para se construir um maior entendimento sobre a relevância da família, sobre a necessidade de apoiá-la, sobre sua influência na incursão dos adolescentes em uma vida de práticas infracio- nais e, sobretudo, o entendimento de que o Estado deve promover políticas públicas, com a finalidade de apoiar às famílias a fim de que estas possam, ao final, acolher seus jovens.

A família ocupa a instância diferenciada quanto à proteção da criança e do adolescente, pois, é através do convívio e do cuidado - ou da sua ausência - que são projetadas as relações e os valores sociais. Mediante a convivência afetiva, a criança e o adolescente podem assimilar, entre outros aspectos, tanto os múltiplos limites quanto as diversas possibilidades de cooperação, de aceitação e tolerância, de alteridade e solidariedade. Compreendendo-se a família como uma instância de vínculo afetivo estável, independente ou não do caráter biológico de sua constituição original, considera-se que o perfil comportamental do adolescente pode ser um indicador da natureza de suas relações familiares.

$\mathrm{O}$ ato de infração do adolescente não pode ser visto de forma isolada de sua história de vida e de sua experiência de violência fami$\operatorname{liar}^{36,37}$. A prática de ato infracional pode vir a ser interpretada como um pedido de socorro do adolescente contra a sociedade e contra si próprio. Este grito em forma de pedido de ajuda, requer mais do que medidas socioeducativas, clama por medidas de proteção que incluam suas famílias. Estas medidas, quando inexistentes ou incipientes, poderão ser exigidas em nível governamental, entre outras iniciativas, pelo próprio órgão do Ministério Público ${ }^{38}$, definidas assim como prioridades nas políticas delineadas pelos conselhos municipais de direito da criança e do adolescente.

As experiências de violência intrafamiliar entre crianças e adolescentes podem ser resignificadas no curso do seu desenvolvimento psicossocial em um sentido construtivo. Neste sentido, tanto a família quanto a sociedade organizada e os operadores do direito podem vir construir novas redes de significação com impacto cultural. O conceito de matrizes socioculturais 
e do seu processo de construção, por parte da pessoa, propõe uma indagação acerca dos nexos causais para estabilidade do envolvimento com o crime, uma vez que a pessoa continuamente reorganiza a experiência por meio de novos modos de compreender sua posição nas circunstâncias, atribuindo sentidos aos circunscritores em seu encontro com o outro ${ }^{39}$.

Refletir sobre o paradigma da proteção integral de crianças e adolescentes ultrapassa, ne- cessariamente, a questão da violência intrafamiliar. É nesta condição de pertencimento a uma família que respeite a criança, que a proteja enquanto pessoa humana em fase peculiar de crescimento e desenvolvimento, independentemente de suas características particulares e de suas singularidades, que o adolescente é convocado à formulação de seu projeto de vida ${ }^{40}$ mediante o qual poderá dar sentido à sua existência na dimensão do respeito para si e para os demais.

\begin{abstract}
The present study aims to discuss experiences of intrafamilial violence reported by adolescents who have committed infractions in the State of Bahia and are abiding by a socioeducational measure of internment. It reviews normative aspects related to the adolescent group and presents the results of an investigation carried out through an agreement with the Children and Youth Court of the city of Salvador. The article approaches the importance of public policies that provide support for the family in the perspective of the human rights, focusing on the growth and development of the adolescent group. The condition of vulnerability faced by the adolescents is related to the necessary effort that must be jointly undertaken by the family, the community and the State to respect their dignity as human beings.
\end{abstract}

Key words: Intrafamilial violence; Right of the child and adolescent; Adolescent in conflict with the law; Family.

\section{REFERÊNCIAS}

1. Njaine K. Violência na mídia e saúde. In: Lima CA, coordenador. Violência faz mal à saúde. Brasília (DF): Ministério da Saúde; 2004. p. 223-31.

2. Postman N. O desaparecimento da infância. Rio de Janeiro: Graphia; 1999.

3. Sanchez RN, Minayo MCS. Violência contra crianças e adolescentes: questão histórica, social e de saúde. In: Lima CA, coordenador. Violência faz mal à saúde. Brasília (DF): Ministério da Saúde; 2004. p. 23-8.

4. Roure GQ. Vidas silenciadas: a violência com crianças e adolescentes. Campinas: Unicamp; 1996.

5. Rosa EM. Radiografia de um processo social: um estudo sobre o discurso jurídico a respeito da violência contra crianças. São Paulo: Casa do Psicólogo; 2004.

6. Finkelhor D, Williams L. Perpetrators. In: Finkelhor D, Williams L, Burns N. Nursery crimes. Newbury Park (CA): Sage; 1993. p. 27-68.

7. Fontes LA. Sexual abuse in nine North American cultures: treatment and prevention. Thousand Oaks (CA): Sage; 1995.

8. Straus MA, Gelles RJ, Steinmetz SK. Behind closed doors: violence in the American famile.
New York (NY): Anchor; 1981.

9. Altoé S, organizador. Sujeito de direitos, sujeito de desejo: direito e psicanálise. Rio de Janeiro: Revinter; 1999.

10. Assis SG. Traçando caminhos numa sociedade violenta: a vida de jovens infratores e seus irmãos não infratores. $2^{\mathrm{a}}$ ed. Rio de Janeiro: Fiocruz; 1999.

11. Assis SG, Constantino P. Filhas do mundo: a infração juvenil feminina. $20^{\mathrm{a}}$ ed. Rio de Janeiro: Fiocruz; 2001.

12. Lima IMSO, Alves VS. Retratos de exclusão social: a família e o adolescente em conflito com a lei na periferia de Salvador, Bahia. In: Petrini JC, Cavalcanti VRS, organizadores. Família, sociedade e subjetividades: uma perspectiva multidisciplinar. Petrópolis: Vozes; 2005. p. 111-31.

13. Méndez EG. Derecho de la infancia-dolescencia en América Latina: de la situación irregular a la protección integral. Bogotá: Convenio Uniandas/Unicef/Fundación Restrepo Barco/ Fundación Fes; 1998.

14. Brasil. Lei no 8.069 , de 13 de julho de 1990. Dispõe sobre o estatuto da criança e do adolescente e dá outras providências. Diário Oficial da União. 16 jul 1990;Seção X 
15. Oliveira EA, Marin AH, Pires FB, Frizzo GB, Ravanello T, Rossato C. Estilos parentais autoritário e democrático-recíproco intergeracionais, conflito conjugal e comportamentos de externalização e internalização. Psicol Reflex Crit. 2002;15(1):1-11.

16. Bandura A, Walters RH. Adolescent aggression. New York (NY): Ronald Press; 1959.

17. Bandura A, Ross D, Ross SA. Transmission of aggression through imitation of aggressive models. J Abnorm Soc Psychol. 1961;63:575-82.

18. Berkowitz L. Some effects of thoughts on antiand prosocial influence of media events: a cognitive neoassociationist analysis. Psychol Bull. 1984;95(3):410-27.

19. Huesmann LR. Psychological processes promoting the relation between exposure to media violence and aggressive behavior by the viewer. J Soc Issues. 1986;42(3):125-39.

20. Glueck S, Glueck E. Unraveling juvenile delinquency. Cambridge (MA): Harvard University Press; 1950.

21. McCord J, McCord W. A follow-up report on the Cambridge-Somerville Youth Study. Ann Am Acad Pol Soc Sci. 1959;(322):89-96.

22. Meeus W, Branje S, Overbeek GJ. Parents and partners in crime: a six-year longitudinal study on changes in supportive relationships and delinquency in adolescence and young adulthood. J Child Psychol Psychiatry. 2004;45(7):1288-98.

23. Gottfredson MR, Hirschi T. A general theory of crime. Stanford (CA): Stanford University Press; 1990.

24. Moffit TE, Caspi A. Comportamento anti-social persistente ao longo da vida e comportamento anti-social limitado à adolescência: seus preditores e suas etiologias. Rev Port Pedagog. 2000;34:65-106.

25. Dias MDF. Adolescentes infratores e não infratores: uma análise comparativa através do CBCL e ESR [dissertação]. São Paulo: UNIFESP/EPM; 2001.

26. Bardin L. Análise de conteúdo. Lisboa: Edições 70; 1970.

27. Costa ACG Lima IMSO. Programa cuidar: livro do professor. Belo Horizonte: Modus Faciendi; 2000.

28. Lima IMSO, Alves VS. A família na proteção integral ao adolescente em conflito com a lei. In: Costa LF, Jacquet C, organizadores. Família em mudança. São Paulo: Companhia Ilimitada; 2004. p. 245-62.

29. Dor EM. Relações interpessoais na família: contribuições para uma análise filosófica das relações familiares. In: Petrini C, Moreira LVC, Alcântara MAR, organizadores. Família XXI: entre pós-modernidade e cristianismo. São Paulo: Companhia Ilimitada; 2003. p. 45-58.

30. Marcílio ML. História social da criança abandonada. São Paulo: Hucitec; 1998.

31. Mounier C, Andujo E. Defensinve functioning of homeless youth in relation to experiences of child maltreatment and cumulative victimization. Child Abuse Negl. 2003;27(10):1187-204.

32. Baldry AC. Bullying in schools and exposure to domestic violence. Child Abuse Negl. 2003;27(7):713-32.

33. Lindsee D. The welfare of children. New York (NY): Oxford University; 1994.

34. Pelton $\mathrm{L}$. The role of material factors in child abuse and neglect. In: Melton G, Barry F, editors. Protecting children from abuse and neglect. New York (NY): Guilford Press; 1994.

35. Berger LM. Income, family characteristics, and physical violence toward children. Child Abuse Negl. 2005;29(2):107-33.

36. Mioto RCT. Famílias e adolescentes autores de atos infracionais: subsídios para uma discussão. In: Veronese JRP, Souza MP, Mioto RCT, organizadores. Infância e adolescência, o conflito com a lei: algumas discussões. Florianópolis: Fundação Boiteux; 2001. p. 91-119.

37. Prates FC. Adolescente infrator: a prestação de serviços à comunidade. Curitiba: Juruá; 2002.

38. Lima IMSO. Direito à saúde: garantia de um direito humano para crianças e adolescentes estudo de caso [tese]. Salvador: Instituto de Saúde Coletiva da Universidade Federal da Bahia; 2002.

39. Silva APS, Rossetti-Ferreira MC. Continuidade/ descontinuidade no envolvimento com o crime: uma discussão crítica da literatura na psicologia do desenvolvimento. Psicol Reflex Crit. 2002;15(3):573-85.

40. Günther I. A adolescência e projeto de vida. In: Schor N, Mota MSFT, Castello Branco V, organizadores. Cadernos juventude, saúde e desenvolvimento. Brasília (DF): Ministério da Saúde; 1999. v. 1, p. 86-92.

Recebido em 22/05/2006

Modificado em 30/06/2006

Aprovado em 19/06/2006 